\title{
Demographic profile and pathway to care in patients with schizophrenia in a tertiary care hospital from western Nepal
}

\author{
Belbase M1, Adhikari J', Khan TA³, Jalan RK ${ }^{4}$
}

\begin{abstract}
1.Asst. Prof. Department of Psychiatry, Nepalgunj Medical College Teaching Hospital, Kohalpur, Nepal 2. Lecturer, Department of Paediatrics, Nepalgunj Medical College Teaching Hospital, Kohalpur, Nepal 3. Lecturer, Department of Psychiatry, Nepalgunj Medical College Teaching Hospital, Kohalpur, Nepal 4. Asst. Prof. Department of Psychiatry, Nepalgunj Medical College Teaching Hospital, Kohalpur, Nepal.
\end{abstract}

E-mail *Corresponding author: mohanbelbase@yahoo.com

\begin{abstract}
Introduction: Schizophrenia is one of the severe mental health problem and its guarded treatment response and association with as the stigma makes it a chronic debilitating personal, family and social problem of all the psychiatric illness. Timely Identification and management of this condition is important as early diagnosis and management gives better treatment response.
\end{abstract}

Methods: This is a descriptive study done in patients attending psychiatry OPD of Nepalgunj Medical College, Kohalpur for 12 months from June 2013 to May 2014.

Results: Out of the 86 study subjects $(n=86)$, males were 54 in number followed by 32 females. The most common age group was 21-40 years representing 46(53.4\%), followed by $41-60$ years $24(28 \%),<20$ years $12(13.9 \%)$ and $>60$ years $4(4.7 \%)$. The most common first contact of the patient with schizophrenia was with faith healers 54 (62.8\%) followed by consultation with psychiatrist 18(20.9\%). Among the study population, 38(44.2\%) visited to the psychiatrist after $>41$ weeks of the beginning of the illness followed by 34(39.5\%) visited in $<10$ weeks of the beginning of the schizophrenia.

Conclusions: Faith healers were the most common first contact person for the patients with schizophrenia followed by psychiatrist. Most of the schizophrenia patients come to psychiatrist after 40 weeks of their illness.

Keywords: Pathway to care, Schizophrenia, Western Nepal

\section{INTRODUCTION}

Mental disorders including schizophrenia are not the exclusive preserve of any special groups; they are truly universal. Mental and behavioral disorders are found in people of all regions, all countries and all societies. ${ }^{1}$

Among all the mental health problems, schizophrenia is the one of the very severe, chronic debilitating problem with disturbance in thought, perception and emotion. This is most commonly associated with stigma not only to the patient and family members but also to mental health workers.

The term schizophrenia was given by Eugen Bleuler in 1911 to denote splitting of psychic functions. ${ }^{2}$ Schizophrenia afflicts $1 \%$ of population and probably it comprises a group of disorders with heterogeneous causes and outcome. $^{3}$

In schizophrenic episode, there will be distortion in thinking and perception with inappropriate or blunted affect. ${ }^{4}$ Schizophrenia patients live 10-12 years less than their normal counter part. 
The Global Burden of Disease, using the measure of disability adjusted life years determined schizophrenia to be one of the 10 leading cause of disease burden. ${ }^{5}$

Treatment of psychiatric illness is complicated by long duration of therapy and the high level of non-compliance (20-50\%). ${ }^{6}$

This study aims how patients with schizophrenia reach to psychiatrist crossing all the twist and turns of traditional faith healers, spiritists, quacks and various channels of modern medicine. Passing through all these channels, the modern medical treatment gets delayed causing long duration of untreated psychosis (DUP). Long DUP is considered to be a reason of poor treatment outcome in schizophrenia. ${ }^{7}$

\section{MATERIAL AND METHOD}

This is a descriptive study done in patients attending psychiatry OPD of Nepalgunj Medical College, Kohalpur for 12 months from June 2013 to May 2014.

All the new cases of schizophrenia came to the OPD were included in the study after taking consent for the study and the publication of the same. Total 86 participants were included in the study. Patients were diagnosed using the ICD-10 (International Classification of Disease, 10 th edition) classification of mental and behavioral disorders, clinical description and diagnostic guidelines. ${ }^{4}$

WHO pathway to care questionnaire was used to record the patients first contact and duration from the onset of symptoms. Patients who did not want to participate in the study, those having schizoaffective disorders, bipolar disorders, depressive disorders and psychoactive substance dependents were excluded from the study group.

Patients who needed psychological intervention were sent to the psychologist working in the same hospital. Needful laboratory investigations were done from the hospital laboratory. The demographic profile was recorded and all the variables were analyzed using SPSS (Statistical Package for Social Studies) software and tabulated in percentage.

\section{RESULT}

Out of the 86 study subjects $(n=86)$, the most common age group was $21-40$ years $46(53.4 \%)$, followed by $41-60$ years $24(28 \%),<20$ years $12(13.9 \%)$ and $>60$ years $4(4.7 \%)$. Male was the most common gender representing 54 patients followed by females numbering 32 .

The most common first contact of the patient with schizophrenia was with faith healers 54 $(62.8 \%)$ followed by consultation with psychiatrist 18(20.9\%), consultation with medical personal (non-psychiatric) $8(9.3 \%)$ and with others $6(7 \%)$. Most of the patients $38(44.2 \%)$ visited to the psychiatrist after more than 40 weeks of the beginning of the illness followed by $34(39.5 \%)$ visited in less than 10 weeks of the beginning of the psychiatric problem.

Table 1: Showing demographic profile of patients having schizophrenia with their age range $(\mathrm{n}=86)$

\begin{tabular}{|l|l|l|l|l|}
\hline \multirow{2}{*}{$\begin{array}{c}\text { Age } \\
\text { (Years) }\end{array}$} & \multicolumn{2}{|c|}{ Gender } & \multicolumn{2}{c|}{$\begin{array}{c}\text { Schizophrenia as per } \\
\text { ICD-10 }\end{array}$} \\
\cline { 2 - 5 } & Male & Female & Number & Percentage \\
\hline$\leq 20$ & 8 & 4 & 12 & 13.9 \\
\hline $21-40$ & 36 & 10 & 46 & 53.4 \\
\hline $41-60$ & 8 & 16 & 24 & 28 \\
\hline$>60$ & 2 & 2 & 4 & 4.7 \\
\hline Total & 46 & 40 & 86 & 100 \\
\hline
\end{tabular}

Table 2. Showing distributions of first contact in patients having schizophrenia (n-86)

\begin{tabular}{|l|l|l|}
\hline Types of first contact & No & $\%$ \\
\hline Faith healers & 54 & 62.8 \\
\hline Psychiatrist & 18 & 20.9 \\
\hline $\begin{array}{l}\text { Medical personals (non } \\
\text { psychiatric) }\end{array}$ & 8 & 9.3 \\
\hline Others & 6 & 7 \\
\hline Total & 86 & 100 \\
\hline
\end{tabular}

Table 3. Showing weeks of first psychiatric contact after the beginning of the problem $\underline{(n=86)}$ 


\begin{tabular}{|l|l|l|}
\hline First psychiatric contact & Number & Percent \\
\hline$<10$ wks & 34 & 39.5 \\
\hline $11-20$ wks & 4 & 4.7 \\
\hline $21-30$ wks & 6 & 6.9 \\
\hline $31-40$ wks & 4 & 4.7 \\
\hline$>40$ wks & 38 & 44.2 \\
\hline Total & 86 & 100 \\
\hline
\end{tabular}

\section{DISCUSSION:}

Out of 86 study subjects, male were 54 followed by 32 females. Schizophrenia is equally common in male and females. This higher number of males in our study could be due to small sample size or higher number of males being brought to medical attention because of gender bias prevailing in our society.

The most common age range for patients with schizophrenia was found to be $21-40$ years, $46(53.4 \%)$ with least age range being $>60$ years of age, $4(4.7 \%)$. This is as per the reference given in most of the standard text books as the schizophrenia is the illness of productive age group. ${ }^{3}$

As per our findings, 54(62.8\%) of schizophrenic patients went to faith healers including shamans, Dhami or spiritists prior to coming to our hospital or psychiatrist. Only 18(20.9\%) patients come to psychiatrist as a first contact point. This finding is important because, this is the reason why most of the patients with schizophrenia present late to modern medical facility. This finding is similar to another study done in Lagos, Nigeria where $68 \%$ of schizophrenia patients went to traditional or faith healers as a first contact. ${ }^{8}$

In similar study done in Bali, out of 54 schizophrenia patients studied, $47(87 \%)$ went to traditional healers prior to coming to mental health facility. ${ }^{9}$

Similarly, we found only $34(39.5 \%)$ schizophrenia patients coming to hospital for psychiatry care after beginning of their recognizable symptoms within 10 weeks while majority of the patients $38(44.2 \%)$ came for the psychiatric care after more than 40 weeks. This delay in hospital or medical care is due to sociocultural belief regarding schizophrenia, misdiagnosis or wrong diagnosis due to lack of trained health workers or specialist services across the most of the rural parts of Nepal.

\section{CONCLUSION:}

Faith healers are the most common first contact person 54(62.8\%) for the patients with schizophrenia followed by psychiatrist $18(20.9 \%)$. Most of the schizophrenia patients $38(44.2 \%)$ present to psychiatrist after more than 40 weeks of recognizable symptoms while only $34(39.5 \%)$ present within 10 weeks.

\section{ACKNOWLEDGEMENTS}

My sincere thanks goes to Lord Buddha Educational Academy, NGMCTH, Kohalpur administration, principal office and neuropsychiatry team for their valuable contribution in the permission of the study, technical guidelines and help in literature review respectively in the study.

\section{REFERENCES:}

1 Park K. Park's textbook of preventive and social medicine. $12^{\text {th }}$ ed. Jabalpur: M/s Banarasidas Bhanot; 2009. P. 734.

2 Hemiltan M. fish's clinical psychopathology sign and symptoms in psychiatry. $2^{\text {nd }} \mathrm{ed}$. England: John wright $\mathcal{E}$ sons; 1985.

3 Sadock BJ, Sadock VA. Kaplan \& Sadock's Synopsis of Psychiatry. 10 th ed. Philadelphia: Lippincott Williams E Wilkins; 2007. p. 467-68.

4 World Health Organization Geneva. The ICD-10 Classification of Mental and Behavioural Disorders, clinical descriptions and diagnostic guidelines. Delhi: A.I.T.B.S. Publishers and Distributors; 2002. P.

5 World Health Organization. Mental health Around the World: Stop exclusion dare to care, World mental health day; 2001.

6 Toughoni G. Pharmacoepidemiology of psychotropic drugs in patients with severe mental disorders in Italy. European journal of clinical pharmacology. 1999; SS(9): p. 685-90.

7 Ahuja N. A Short text book of psychiatry. $6^{\mathrm{TH}}$ ed. New Delhi: Jaypee Brothers medical publisher(p) LTD; 2006. P 67

8 Andeosun I, Adegbohun AA, Adewumi TA, et al. The Pathways to the First Contact with the Mental Health Services among patients with Schizophrenia in Lagos,Nigeria. Schizophrenia Research and Treatment:volume 2013 (2013).[ internet], Cited may 2014, Available on http:// $d x$. Doi. Org/10.1155/2013/769161

9 KuriharaaT, Kato $M$, Reverger $R$, et al. Pathway to psychiatry care in Bali. J of psychiatry and clinical neuroscience. April 2006, Vol 60(2): P. 204-10. 